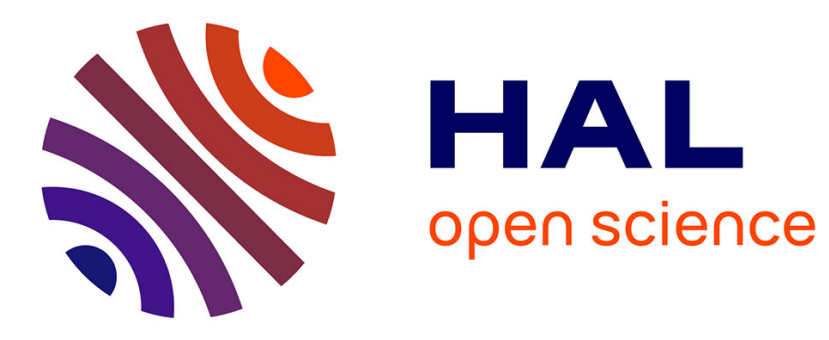

\title{
Substituent effect in unsymmetrical lutetium bisphthalocyanines: a DFT analysis
}

Samia Kahlal, Arnaud Mentec, Annick Pondaven, Maurice L'Her, Jean-Yves Saillard

\section{- To cite this version:}

Samia Kahlal, Arnaud Mentec, Annick Pondaven, Maurice L'Her, Jean-Yves Saillard. Substituent effect in unsymmetrical lutetium bisphthalocyanines: a DFT analysis. New Journal of Chemistry, 2009, 33 (3), pp.574-582. 10.1039/B810131K . hal-00861644

\section{HAL Id: hal-00861644 https://hal.science/hal-00861644}

Submitted on 13 Sep 2013

HAL is a multi-disciplinary open access archive for the deposit and dissemination of scientific research documents, whether they are published or not. The documents may come from teaching and research institutions in France or abroad, or from public or private research centers.
L'archive ouverte pluridisciplinaire HAL, est destinée au dépôt et à la diffusion de documents scientifiques de niveau recherche, publiés ou non, émanant des établissements d'enseignement et de recherche français ou étrangers, des laboratoires publics ou privés. 


\title{
Substituent effect in unsymmetrical lutetium bisphthalocyanines: a DFT analysis $\dagger$
}

\author{
Samia Kahlal, ${ }^{a}$ Arnaud Mentec, ${ }^{b}$ Annick Pondaven, ${ }^{b}$ Maurice L'Her ${ }^{* b}$ \\ and Jean-Yves Saillard ${ }^{* a}$
}

Received (in Montpellier, France) 7th July 2008, Accepted 17th October 2008

First published as an Advance Article on the web 8th December 2008

DOI: $10.1039 / \mathbf{b 8 1 0 1 3 1 k}$

DFT calculations have been carried out on a series of unsymmetrical bisphthalocyanine lutetium complexes in which one of the ligands is substituted by 8 or 16 chlorine atoms. It is shown that their unpaired electron is predominantly localized on the non-substituted ligand. An orbital explanation is provided to rationalize this effect. A good agreement is found between the computed and experimental ionization potentials and electroaffinities and the redox potentials of a closely related series, as well as between their TDDFT-computed and experimental UV-visible transitions which are analysed.

\section{Introduction}

The lanthanide bisphthalocyanines are sandwich complexes having two organic redox centers, the macrocyclic units, linked together by the metal ion, Ln(III), which apparently does not play a leading role as most properties are associated with the $\pi$-electron orbitals: the complex is equivalent to $\mathrm{Ln}^{3+}$ linked to two ligands, one phthalocyanine ring, formally $\mathrm{Pc}^{2-}$, and one oxidized macrocycle, formally $\mathrm{Pc}^{\bullet-}$. The close proximity of the two phthalocyanines, $2.69 \AA$ in the lutetium derivative, ${ }^{2}$ allows the delocalization of the unpaired electron over both the macrocyclic rings i.e., two equivalent $\mathrm{Pc}^{1.5-}$ ligands, a fact which is now well accepted but has been debated, ${ }^{2,3}$ mainly because the two phthalocyanines have different shapes in the crystalline forms, one being domed and the other one flatter. This could be caused by packing in the solid phase or by differences in the environment of each of the two phthalocyanines. It also makes sense that, in an isotropic environment, in vacuum for example, the electron must be equally shared by the two $\pi$-systems of the symmetrical $\mathrm{Lu}(\mathrm{Pc})_{2}$ molecule. However, it is reasonably expected that asymmetry in the conjugated $\pi$-macrocycles of the sandwich complex would influence the electron density. Numerous molecules coupling two phthalocyanines differently substituted have been synthesized. ${ }^{4,5}$ From the electronic absorption spectra of phthalocyaninato-naphthalocyaninato $\mathrm{Lu}^{\text {III }}$ complexes, it has been concluded that the electron is delocalized and that the hole density is higher on the naphthalocyanine. ${ }^{3 a, 6}$ Near IR and Raman spectroscopies of heteroleptic complexes allowed some authors to conclude that the orbital levels keep

${ }^{a}$ Sciences Chimiques de Rennes, UMR 6226 CNRS-Université de Rennes 1, Avenue du Général Leclerc, 35042 Rennes Cedex, France

${ }^{b}$ Laboratoire de Chimie, Electrochimie Moléculaires et Chimie Analytique, UMR 6521 CNRS-Université de Bretagne Occidentale, 6 avenue Victor Le Gorgeu-CS93837, 29238 Brest Cedex 3, France

$\dagger$ Electronic supplementary information (ESI) available: Atomic Cartesian coordinates of the optimized compounds (Table S1) and distances between the $\left(\mathrm{N}_{\mathrm{p}}\right)_{4}$ plane and the planes formed by the various ligand type atoms (Table S2). See DOI: 10.1039/b810131k the porphyrin and phthalocyanine characters, a spectroelectrochemical study indicating that oxidation involves the porphyrin ring, reduction occurring on the phthalocyanine. ${ }^{5,7-10}$ However, from IR and Raman spectroscopies of numerous unsymmetrically substituted bisphthalocyanines, studied under their neutral as well as their reduced and oxidized forms, we have been unable to find any genuine marker of the redox state of the phthalocyanine units. This is why experimental works, as well as a theoretical study, have been undertaken to improve knowledge about the charge partitioning in heteroleptic bisphthalocyaninato lutetium complexes.

Unsymmetrical lutetium bisphthalocyanines, bearing four electron donor groups, tert-butyl substituents, on one ring and four, eight or sixteen acceptors, $\mathrm{Cl}$, on the second unit, have been synthesized. They show very unusual properties, evidenced by spontaneous dimerization, in solutions at ambient temperature, and also by their electrochemical properties. ${ }^{11} \mathrm{It}$ appeared interesting to know whether this could be related to the influence of asymmetry on the charge and spin densities over the two macrocycles. Numerous theoretical calculations have already been performed for phthalocyanines and phthalocyanine complexes of which selected references are provided herein. ${ }^{12-28}$ However, to our knowledge, no density functional theory (DFT) calculations have been performed on bisphthalocyanine lutetium complexes in different oxidation states and no complete MO rationalization of the electronic structure in unsymmetrical complexes has been undertaken so far. In the following, we analyze by means of DFT calculations the bonding and the localization of the unpaired electron in $\mathrm{LuPc}_{2}$ and the perturbation caused by the presence of chlorine substituents on one of the Pc ligands. The investigated compounds, namely $\mathrm{LuPc}_{2}, \operatorname{PcLu}\left[\mathrm{Pc}\left(\mathrm{p}-\mathrm{Cl}_{8}\right)\right]$, $\mathrm{PcLu}\left[\mathrm{Pc}\left(\mathrm{np}-\mathrm{Cl}_{8}\right)\right]$ and $\mathrm{PcLu}\left[\mathrm{PcCl}_{16}\right]$, are shown in Scheme 1 . Calculations have been carried out on the neutral, cationic and anionic forms of each bisphthalocyanine. The UV-visible spectra of all these complexes have been also computed at the TDDFT level and compared to the experimental ones. Details of the calculations are given below. 

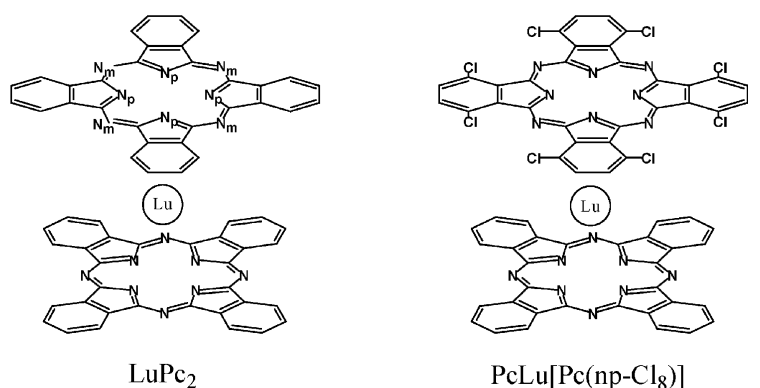

$\mathrm{LuPc}_{2}$

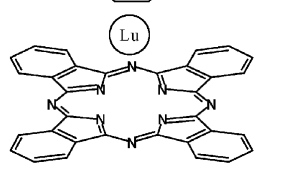

$\mathrm{PcLu}\left[\mathrm{Pc}\left(\mathrm{np}-\mathrm{Cl}_{8}\right)\right]$
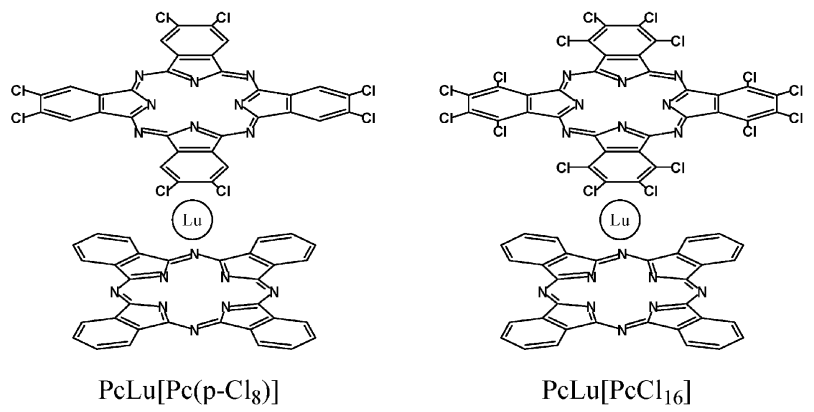

Scheme 1

\section{Result and discussion}

\section{The free phthalocyanine ligands}

In order to derive the electronic structure of the above mentioned bisphthalocyanine complexes from that of their free ligands, considered here as hypothetical building block units for the whole complexes, we have carried out calculations at the same level of theory on the neutral and dianionic forms of the isolated ligand fragments, i.e., $[\mathrm{Pc}]^{0 / 2-},\left[\mathrm{Pc}\left(\mathrm{p}-\mathrm{Cl}_{8}\right)\right]^{0 / 2-}$, $\left[\mathrm{Pc}\left(\mathrm{np}-\mathrm{Cl}_{8}\right)\right]^{0 / 2-}$ and $\left[\mathrm{PcCl}_{16}\right]^{2-} . D_{4 \mathrm{~h}}$ symmetry and singlet states were firstly assumed. In terms of level ordering, energy gaps and orbital localization, our results match, at least qualitatively, those of previous investigations on $[\mathrm{Pc}]^{0 / 2-}$ obtained at various levels of theory. ${ }^{13 b, 16 a, 23}$ To our knowledge, no optimized structures of free $[\mathrm{Pc}]^{0 / 2-}$ have been published so far. Nevertheless, our metrical data (see ESI $\dagger$ ) are consistent with the most recent results on metal-complexes MPc and free $\mathrm{H}_{2} \mathrm{Pc}$ species. ${ }^{19 c, 20 a, b, d, e, 24 c, 28}$ The MO diagrams of the computed dianionic forms are shown in Fig. 1.

They exhibit two nearly degenerate non-bonding HOMO's of $\mathrm{a}_{1 \mathrm{u}}$ and $\mathrm{b}_{1 \mathrm{~g}}$ symmetry lying above an $\mathrm{a}_{2 \mathrm{u}} \mathrm{MO}$, their relative ordering depending on the nature of the substituent $(\mathrm{H}$ or $\mathrm{Cl})$ at $\mathrm{C}_{\gamma}$. These orbitals are plotted in Fig. 2 in the case of $\mathrm{Pc}^{2-}$. They are very similar in the case of the other substituted phthalocyanines, in which they exhibit only small chlorine participation.

It is noteworthy that the $\pi$-type $\mathrm{a}_{1 \mathrm{u}}$ MO has no participation by symmetry of the nitrogen atoms and exhibits a pseudo-8-fold symmetry on the macrocycle. On the other hand, the $\sigma$-type $b_{1 g}$ MO can be viewed as the out-of-phase combination of the four ligand nitrogen lone-pairs. This orbital is expected to be strongly involved in the phthalocyanine complexation by a metal. The $\pi$-type $\mathrm{a}_{2 \mathrm{u}}$ HOMO-2 has also significant localization on the four basic nitrogen atoms. Thus, the $b_{1 g}$ orbital (and to a

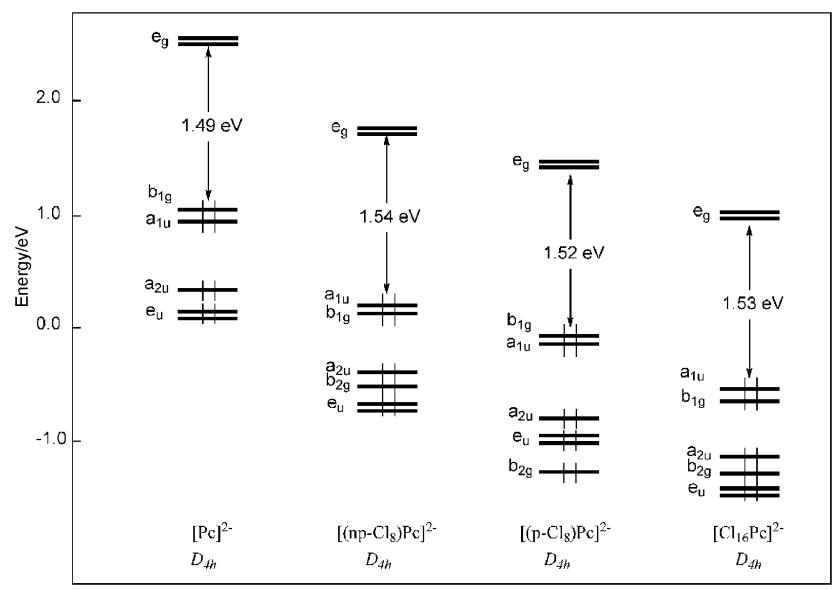

Fig. 1 One-electron energy diagrams of the dianionic forms of the free phthalocyanine ligands. Only the highest occupied and lowest unoccupied levels are considered.

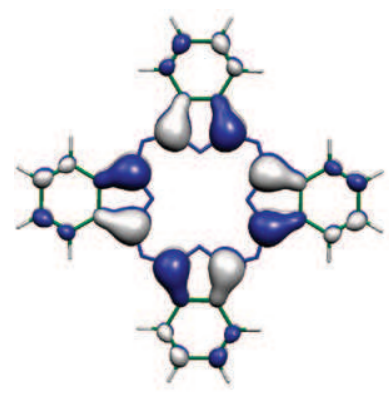

$\mathrm{a}_{1 \mathrm{u}}$

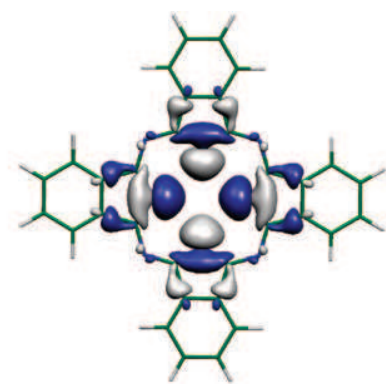

$b_{1 g}$

$$
\begin{gathered}
{[\mathrm{Pc}]^{2-}} \\
D_{\text {th }}
\end{gathered}
$$

Fig. 2 Plots of the two highest occupied MO's of $\mathrm{Pc}^{2-}$.

lesser extend the $\mathrm{a}_{2 \mathrm{u}} \mathrm{MO}$ ) is expected to be stabilized upon metal complexation, whereas the $\mathrm{a}_{1 \mathrm{u}}$ orbital will remain unperturbed.

The doubly oxidized phthalocyaninato ligands, with two electrons less are the neutral phthalocyanines $\mathrm{Pc}^{0}$ which exhibit, in the assumed $D_{4 \mathrm{~h}}$ symmetry, a very small $\operatorname{HOMO}\left(b_{1 \mathrm{~g}}\right) / \operatorname{LUMO}\left(\mathrm{a}_{1 \mathrm{u}}\right)$ gap, with no significant change in the ordering of the other levels when compared to their dianions. It turns out that this small HOMO/LUMO gap induces second-order Jahn-Teller instability for the singlet state of the neutral $D_{4 \mathrm{~h}}$ species which are all found to be more stable in a distorted $D_{2 \mathrm{~h}}$ structure by $\sim 0.5 \mathrm{eV}$. On the other hand, the dianionic species are more stable in the $D_{4 \mathrm{~h}}$ symmetry.

An important feature arising from a look at Fig. 1 is the variation of energy of the frontier orbital levels with respect to the number of chlorine substituents. The larger the number of chlorines, the lower the energy of the phthalocyanine frontier orbitals. This trend is independent of the phthalocyanine oxidation state. For example, the energy of the $\mathrm{a}_{1 \mathrm{u}}$ level varies in the order $\mathrm{Pc}>\mathrm{Pc}\left(\mathrm{p}-\mathrm{Cl}_{8}\right) \approx \mathrm{Pc}\left(\mathrm{np}-\mathrm{Cl}_{8}\right)>\mathrm{PcCl}_{16}$ in both the neutral and dianionic species. This chlorine dependence is the consequence of the halogen electro-attracting inductive effect which tends to stabilize the phthalocyanine frontier orbital. Thus, it largely overcomes the halogen $\pi$-donating 
effect which tends to destabilize the same levels. The difference between the frontier orbital energies of the $\mathrm{Pc}\left(\mathrm{p}-\mathrm{Cl}_{8}\right)$ and $\mathrm{Pc}\left(\mathrm{np}-\mathrm{Cl}_{8}\right)$ isomers is due to the closeness to the $\mathrm{N}_{\mathrm{p}}$ atoms (see Scheme 1) of the chlorine substituents in the latter which renders stronger the inductive effect.

\section{The bisphthalocyanine lutetium complexes}

We start the analysis by looking at the $\left(\mathrm{LuPc}_{2}\right)^{+/ 0 /-1}$ series. Although the Ln(III) bisphthalocyanine complexes usually crystallize in the staggered pseudo- $D_{4 \mathrm{~d}}$ conformations, ${ }^{2,29}$ geometry optimizations were made starting from the $D_{4 \mathrm{~h}}$ (eclipsed) and $D_{4 \mathrm{~d}}$ (staggered) conformations, but assuming lower $C_{4 \mathrm{v}}$ or $C_{2}$ symmetry constraint, thus allowing distortion away from the more symmetrical conformations. In any case, the lowest energy was found to correspond to the staggered conformation (by $\sim 0.6 \mathrm{eV}$ ) with very little or no significant distortion away from the ideal $D_{4 \mathrm{~d}}$ symmetry. It should be noted that optimization of the less stable eclipsed conformation leads to unsymmetrical phthalocyanines in the case of $\left(\mathrm{LuPc}_{2}\right)^{+/ 0 /-1}$. The results reported here correspond to the more stable staggered conformation optimized assuming $C_{4 \mathrm{v}}$ symmetry constraint. Relevant calculated data are given in Table 1.

The optimized geometry of the neutral form is shown in Fig. 3, some relevant metrical data are given in Table 1 and the MO diagrams of the $\left(\mathrm{LuPc}_{2}\right)^{+/ 0 /-1}$ series are sketched in Fig. 4. It should be noted that the optimized metric data of $\mathrm{LuPc}_{2}$ are in a good agreement with the available experimental ones, with slightly longer optimized $\mathrm{Lu}-\mathrm{N}_{\mathrm{p}}$ distances $\left(2.41 \AA\right.$ vs. $2.38 \AA$ ). ${ }^{2}$ The slight longitudinal elongation of the molecule with the

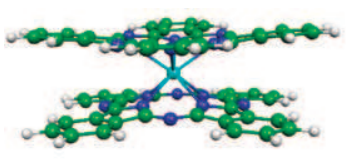

$\mathrm{LuPc}_{2}$ $C_{4 v}$

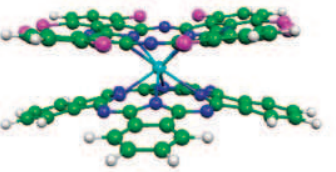

$\mathrm{PcLu}\left[\mathrm{Pc}\left(\mathrm{np}-\mathrm{Cl}_{8}\right)\right]$

$C_{4}$

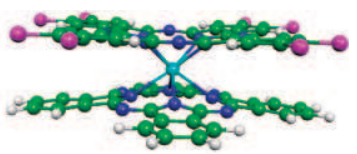

$\operatorname{PcLu}\left[\mathrm{Pc}\left(\mathrm{p}-\mathrm{Cl}_{8}\right)\right]$ $C_{4 v}$

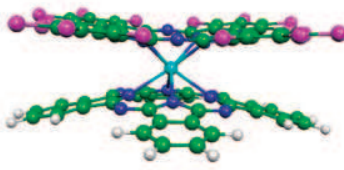

$\mathrm{PcLu}\left[\mathrm{PcCl}_{16}\right]$

$C_{4}$
Fig. 3 Optimized structures of $\mathrm{LuPc}_{2}, \mathrm{PcLu}\left[\mathrm{Pc}\left(\mathrm{p}-\mathrm{Cl}_{8}\right)\right], \mathrm{PcLu}\left[\mathrm{Pc}\left(\mathrm{np}-\mathrm{Cl}_{8}\right)\right]$ and $\mathrm{PcLu}\left[\mathrm{PcCl}_{16}\right]$.

increasing number of electrons occupying the $2 \mathrm{a}_{2}$ level is consistent with the $\pi-\pi$ antibonding character of this orbital. This effect has been proved experimentally on a related terbium series. ${ }^{32}$ On the other hand, the Pc doming is quite insensitive to the oxidation state of the complex (Table 1), as exemplified by the average intra-ligand distances between the $\left(\mathrm{N}_{\mathrm{p}}\right)_{4}$ and the $\left(\mathrm{C}_{\gamma}\right)_{4}$ planes which all lie between $0.55 \AA$ and $0.65 \AA$ (see Table $\mathrm{S} 2 \uparrow$ for full metrical data describing Pc doming).

The singlet ground states of the cationic and anionic forms are associated with large HOMO/LUMO gaps. They differ from each other by the occupation of the $2 \mathrm{a}_{2}$ level (also labeled

Table 1 Major computed data for the $\left(\mathrm{LuPc}_{2}\right)^{+/ 0 /-1}, \operatorname{PcLu}\left[\mathrm{Pc}\left(\mathrm{p}-\mathrm{Cl}_{8}\right)\right]^{+/ 0 /-1}, \quad \mathrm{PcLu}\left[\mathrm{Pc}\left(\mathrm{np}-\mathrm{Cl}_{8}\right)\right]^{+/ 0 /-1}$ and $\mathrm{PcLu}\left[\mathrm{PcCl} \mathrm{l}_{16}\right]^{+/ 0 /-1}$ series (see computational details). Values in parentheses are experimental distances taken from ref. 2

\begin{tabular}{|c|c|c|c|c|c|c|c|c|c|c|c|c|}
\hline & \multicolumn{3}{|c|}{$\underline{\left[\mathrm{LuPc}_{2}\right]^{\mathrm{q}} C_{4 \mathrm{v}}}$} & \multicolumn{3}{|c|}{$\operatorname{PcLu}\left[\operatorname{Pc}\left(\mathrm{p}-\mathrm{Cl}_{8}\right)\right]^{\mathrm{q}} C_{4 \mathrm{v}}$} & \multicolumn{3}{|c|}{$\underline{\operatorname{PcLu}\left[\operatorname{Pc}\left(\mathrm{np}-\mathrm{Cl}_{8}\right)\right]^{\mathrm{q}} C_{4 \mathrm{v}}}$} & \multicolumn{3}{|c|}{ 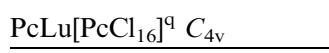 } \\
\hline & $q=+1$ & $=0$ & $=-1$ & $q=+1$ & $=0$ & $=-1$ & $q=+1$ & $=0$ & $=-1$ & $q=+1$ & $=0$ & $=-1$ \\
\hline $\begin{array}{l}\text { HOMO-LUMO } \\
\text { Gap/eV }\end{array}$ & 0.71 & 0.88 & 0.92 & 0.70 & 0.85 & 0.83 & 0.49 & 0.92 & 0.90 & 0.48 & 0.87 & 0.76 \\
\hline $\begin{array}{l}\text { First ionisation } \\
\text { energy/eV }\end{array}$ & & 5.74 & & & 6.12 & & & 5.98 & & & 6.21 & \\
\hline $\begin{array}{l}\text { Electronic } \\
\text { affinity/eV }\end{array}$ & & 3.38 & & & 3.74 & & & 3.64 & & & 3.93 & \\
\hline$\mu /$ Debye & 0.00 & 0.05 & 0.14 & 2.99 & 2.98 & 1.99 & 2.26 & 2.74 & 1.71 & 3.98 & 5.35 & 3.61 \\
\hline $\begin{array}{l}\mathrm{Lu}-\mathrm{N}_{\mathrm{p}} \\
\text { distances } / \AA^{a}\end{array}$ & 2.408 & $\begin{array}{l}2.415 \\
(2.372)\end{array}$ & $\begin{array}{l}2.419 \\
(2.392)\end{array}$ & 2.397 & 2.415 & 2.439 & 2.407 & 2.420 & 2.445 & 2.414 & 2.425 & 2.458 \\
\hline & 2.398 & $\begin{array}{l}2.418 \\
(2.387)\end{array}$ & $\begin{array}{l}2.416 \\
(2.374)\end{array}$ & 2.390 & 2.400 & 2.407 & 2.396 & 2.405 & 2.410 & 2.397 & 2.403 & 2.399 \\
\hline $\begin{array}{l}(\mathrm{Np})_{4} \cdots(\mathrm{Np})_{4} \\
\text { interplane distance } / \AA\end{array}$ & 2.730 & $\begin{array}{l}2.781 \\
(2.690)\end{array}$ & $\begin{array}{l}2.770 \\
(2.701)\end{array}$ & 2.716 & 2.755 & 2.798 & 2.701 & 2.731 & 2.764 & 2.719 & 2.736 & 2.770 \\
\hline $\mathrm{Pc}^{\mathrm{Cl}}$ doming angle ${ }^{\circ b}$ & 172 & 173 & 172 & 173 & 174 & 174 & 171 & 171 & 171 & 173 & 172 & 172 \\
\hline $\begin{array}{l}\text { Pc doming angle/ } /{ }^{\circ b} \\
\text { Mulliken net charges }\end{array}$ & 172 & 173 & 172 & 172 & 173 & 173 & 167 & 168 & 166 & 169 & 167 & 167 \\
\hline $\mathrm{Lu}$ & 1.56 & 1.55 & 1.57 & 1.56 & 1.56 & 1.56 & 1.60 & 1.60 & 1.61 & 1.61 & 1.63 & 1.63 \\
\hline$P c^{\mathrm{Cl}}$ & -0.28 & -0.77 & -1.28 & -0.39 & -0.90 & -1.35 & -0.39 & -0.92 & -1.36 & -0.48 & -1.02 & -1.42 \\
\hline$P c$ & -0.28 & -0.78 & -1.29 & -0.18 & -0.66 & -1.21 & -0.21 & -0.69 & -1.25 & -0.13 & -0.61 & -1.21 \\
\hline$\% 2 \mathrm{a}_{2} \mathrm{Pc}^{\mathrm{Cl}}$ & 50 & 50 & 50 & 46 & 41 & 31 & 46 & 41 & 21 & 43 & 34 & 16.5 \\
\hline $\begin{array}{l}\% 2 \mathrm{a}_{2} \mathrm{Pc} \\
\text { Spin density }\end{array}$ & 50 & 50 & 50 & 54 & 59 & 69 & 54 & 59 & 74 & 57 & 66 & 83.5 \\
\hline $\mathrm{Lu}$ & & 0 & & & 0 & & & 0 & & & & \\
\hline $\mathrm{Pc}^{\mathrm{Cl}}$ & & 0.50 & & & 0.40 & & & 0.39 & & & 0.32 & \\
\hline $\mathrm{Pc}$ & & 0.50 & & & 0.60 & & & 0.61 & & & 0.68 & \\
\hline
\end{tabular}

${ }^{a}$ Bold values correspond to the substituted $\mathrm{Pc}^{\mathrm{Cl}}$ ligand. ${ }^{b}$ The doming angle is defined as the angle between the $(\mathrm{Np})_{4}$ plane and each of the planar $\mathrm{C}_{8} \mathrm{~N}$ pyrrolic units. 


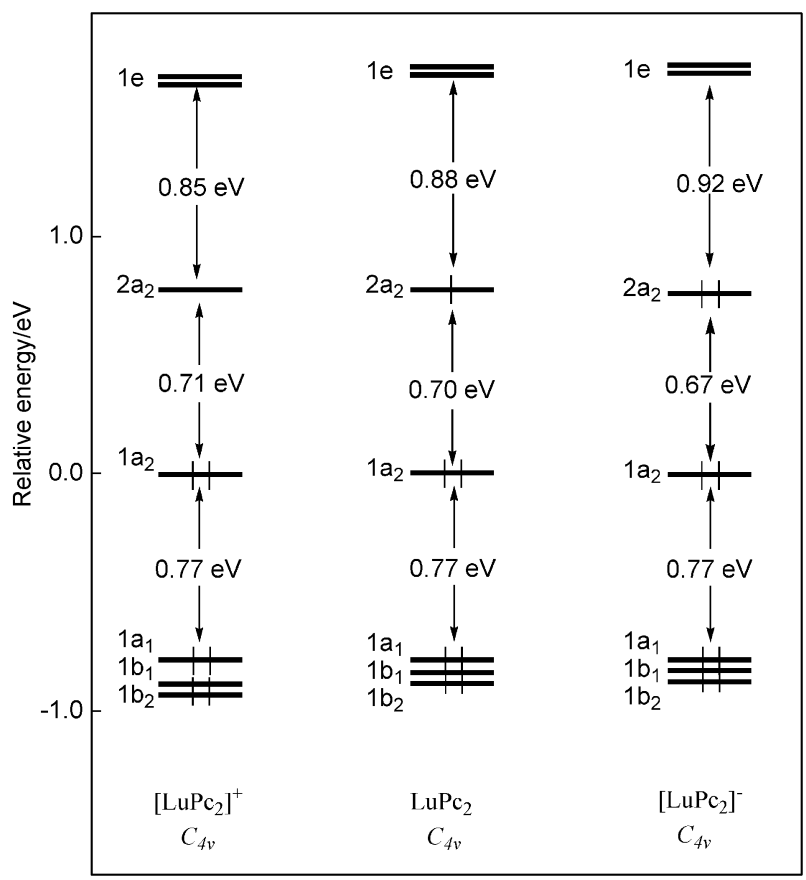

Fig. 4 MO diagrams of the $\left(\mathrm{LuPc}_{2}\right)^{+/ 0 /-1}$ models. The energy of the $1 \mathrm{a}_{2}$ level has been arbitrarily set to zero in the three diagrams.

$\mathrm{a}_{2}$ in the $D_{4 \mathrm{~d}}$ symmetry). This orbital, which is the SOMO of the neutral species, is shown in Fig. 5. It has no metal participation by symmetry and is equally localized on both Pc ligands. Consistently, the spin density on each Pc ligand is equal to 0.5 . Any attempt to dissymmetrize the SOMO by rendering non-equivalent the Pc ligands in the geometry optimization process lead to the same symmetrically delocalized mixed valence.

Although this result is fully consistent with the recent conclusion of a near-infrared intervalence band analysis on $\mathrm{LuPc}_{2},{ }^{30}$ one may argue that the considered level of theory tends to systematically favor delocalized distributions, due to the self-interaction errors contained in the DFT formalism. Since the aim of this paper is not to deeply analyze the

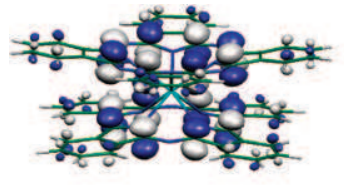

$\mathrm{LuPc}_{2}$

$C_{\downarrow v}$

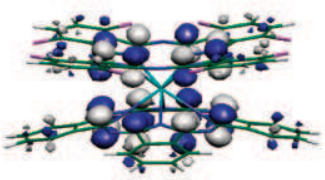

$\operatorname{PcLu}\left[\mathrm{Pc}\left(\mathrm{np}-\mathrm{Cl}_{8}\right)\right]$

$C_{4 v}$

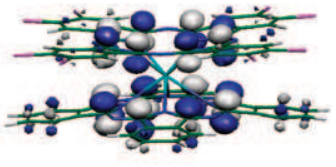

$\operatorname{PcLu}\left[\mathrm{Pc}\left(\mathrm{p}-\mathrm{Cl}_{8}\right)\right]$

$C_{\text {tv }}$

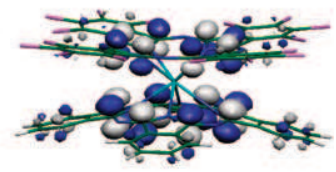

$\mathrm{PcLu}\left[\mathrm{PcCl}_{16}\right]$
Fig. 5 Plots of the SOMO's of $\mathrm{LuPc}_{2}, \mathrm{PcLu}\left[\mathrm{Pc}\left(\mathrm{p}-\mathrm{Cl}_{8}\right)\right], \mathrm{PcLu}\left[\mathrm{Pc}\left(\mathrm{np}-\mathrm{Cl}_{8}\right)\right]$ and $\mathrm{PcLu}\left[\mathrm{PcCl}_{16}\right]$. mixed-valent nature of $\mathrm{LuPc}_{2}$, but mainly investigate its unsymmetrical relatives, we did not carry out calculations on $\mathrm{LuPc}_{2}$ at a higher level of theory. Nevertheless, taken as a whole, the DFT results, the experimental X-ray structure ${ }^{2}$ and the near-infrared data ${ }^{30}$ suggest that $\mathrm{LuPc}_{2}$ has a delocalized or nearly delocalized mixed valence.

As said above, the $2 \mathrm{a}_{2} \mathrm{SOMO}$ of $\mathrm{LuPc}_{2}$ has no metal (including $4 \mathrm{f}$ ) character. As one can see in Fig. 5, it is the out-of-phase combination on the $\pi$-type $\mathrm{a}_{1 \mathrm{u}} \mathrm{HOMO} / \mathrm{SOMO}$ of $\mathrm{Pc}^{-2 /-1}$ (see Fig. 1 and 2). The corresponding in-phase combination ( $\mathrm{b}_{1}$ in $D_{4 \mathrm{~d}}$ symmetry) is the next lower $1 \mathrm{a}_{2} \mathrm{MO}$, which is occupied in the three $\left(\mathrm{LuPc}_{2}\right)^{+/ 0 /-1}$ species. Thus, the two highest occupied orbitals of $\mathrm{LuPc}_{2}$ do not depend on the metal-ligand interaction since they are only combinations of the $\mathrm{a}_{1 \mathrm{u}}$ Pc frontier orbitals (see left side of Scheme 2) with no metal participation. The energy splitting between these two combinations is not negligible $(\sim 0.7 \mathrm{eV})$, resulting from significant overlap between the two $\mathrm{Pc} \mathrm{a}_{1 \mathrm{u}}$ orbitals. This splitting is about the same in the eclipsed conformation due to the near 8-fold symmetry (Fig. 2) of the Pc $\mathrm{a}_{1 \mathrm{u}}$ orbitals. Therefore, the occupation number of the $\mathrm{a}_{2}$ system in the $\left(\operatorname{LuPc}_{2}\right)^{+/ 0 /-1}$ series has no significant effect on the rotational conformation preference, which, as well as the macrocycle doming, has been shown to be essentially driven by the necessity of maximizing metal-ligand bonding together with minimizing the steric hindrance between the ligands. ${ }^{33}$ On the other hand, because of the $\pi-\pi$ antibonding nature of the $2 \mathrm{a}_{2} \mathrm{MO}$, its occupation number has some effect on the distance between the two Pc ligands. This result as well as the energy diagrams of Fig. 4 agree with recently published DFT calculations on $\left(\mathrm{YPc}_{2}\right)^{ \pm} .18 b$

Unlike the $\left(\mathrm{LuPc}_{2}\right)^{+/ 0 /-1}$ series, the chlorinated relatives $\mathrm{PcLu}\left[\mathrm{Pc}\left(\mathrm{p}-\mathrm{Cl}_{8}\right)\right]^{+/ 0 /-1}, \mathrm{PcLu}\left[\mathrm{Pc}\left(\mathrm{np}-\mathrm{Cl}_{8}\right)\right]^{+/ 0 /-1}$ and $\mathrm{PcLu}\left[\mathrm{PcCl}_{16}\right]^{+/ 0 /-1}$ have non-equivalent ligands. They were also found to be more stable in the staggered conformation, assuming $C_{4 \mathrm{v}}$ symmetry constraint. Relevant computed data are given in Table 1. The optimized structures and the MO diagrams corresponding to the neutral species are shown in Fig. 3 and Fig. 6, respectively. Although unsymmetrical, the substituted complexes have quite similar structural characteristics to their non-substituted relatives. The $\mathrm{Pc}\left(\mathrm{np}-\mathrm{Cl}_{8}\right)$ and $\mathrm{PcCl}_{16}$

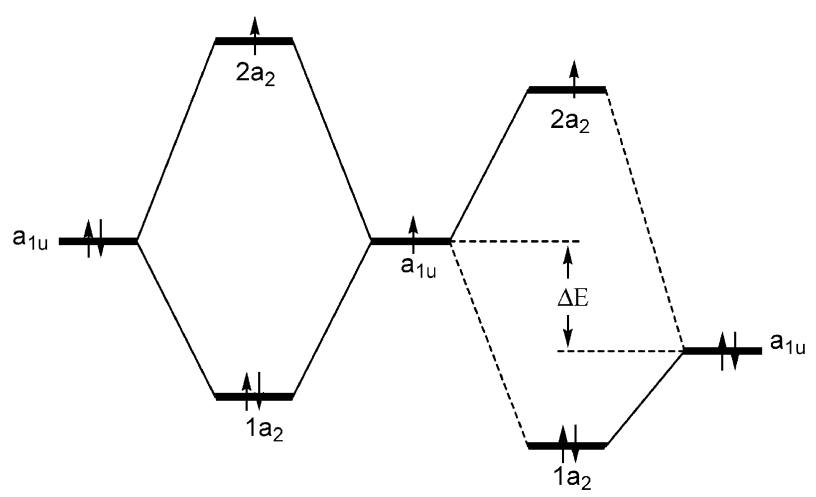

$\begin{array}{ccccc}{[\mathrm{Pc}]^{2-}} & \mathrm{LuPc}_{2} & {[\mathrm{Pc}]^{-}} & \mathrm{PcLu}\left(\mathrm{PcCl}_{\mathrm{n}}\right) & {\left[\mathrm{PcCl}_{\mathrm{n}}\right]^{2-}} \\ D_{4 h} & C_{4 v} & D_{4 h} & C_{4 v} & D_{4 h}\end{array}$ 


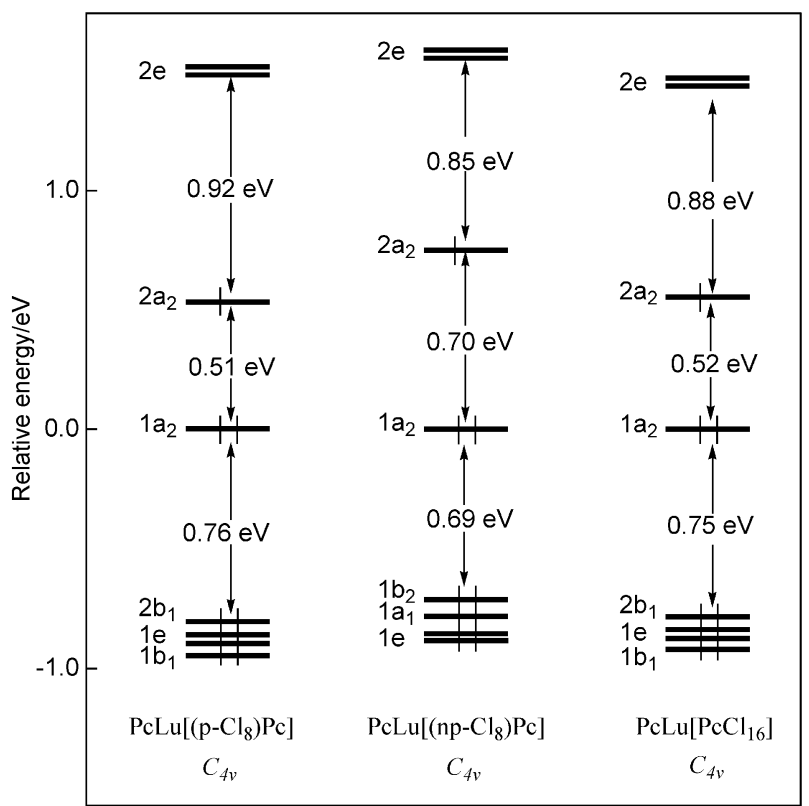

Fig. $6 \mathrm{MO}$ diagrams of $\mathrm{PcLu}\left[\mathrm{Pc}\left(\mathrm{p}-\mathrm{Cl}_{8}\right)\right], \operatorname{PcLu}\left[\mathrm{Pc}\left(\mathrm{np}-\mathrm{Cl}_{8}\right)\right]$ and $\mathrm{PcLu}\left[\mathrm{PcCl}_{16}\right]$. The energy of the $1 \mathrm{a}_{2}$ level has been arbitrarily set to zero in the three diagrams.

complexed ligands exhibit a more pronounced doming than their Pc counterpart, whereas $\mathrm{Pc}\left(\mathrm{p}-\mathrm{Cl}_{8}\right)$ does not. Clearly, the np position of the chlorine substituents (Scheme 1) on the macrocycle has a significant effect on its steric hindrance. Consistently, the $\mathrm{Lu}-\mathrm{N}_{\mathrm{p}}\left(\mathrm{Pc}^{\mathrm{Cl}}\right)$ distances are larger in the case of $\mathrm{Pc}\left(\mathrm{np}-\mathrm{Cl}_{8}\right)$ and $\mathrm{PcCl}_{16}$ than in the case of $\mathrm{Pc}\left(\mathrm{p}-\mathrm{Cl}_{8}\right)$. On the other hand, the Lu- $\mathrm{N}_{\mathrm{p}}(\mathrm{Pc})$ distances of the three substituted complexes are almost equal and slightly shorter than in the non-substituted $\mathrm{LuPc}_{2}$ species, whereas the doming of the unsubstituted Pc ligand is more pronounced than that of the substituted $\mathrm{Pc}^{\mathrm{Cl}}$ one (Table 1). For example, in $\mathrm{PcLu}\left[\mathrm{PcCl}_{16}\right]$ the average distance between the $\left(\mathrm{N}_{\mathrm{p}}\right)_{4}$ and the $\left(\mathrm{C}_{\gamma}\right)_{4}$ planes in the $\mathrm{Pc}$ and $\mathrm{PcCl}_{16}$ ligands is $1.07 \AA$ and $0.66 \AA$, respectively (see Table $\mathrm{S} 2 \dagger$ for full metrical data associated with ligand doming).

As for $\mathrm{LuPc}_{2}$, the two highest occupied orbitals of $\mathrm{PcLu}\left[\mathrm{Pc}\left(\mathrm{p}-\mathrm{Cl}_{8}\right)\right], \mathrm{PcLu}\left[\mathrm{Pc}\left(\mathrm{np}-\mathrm{Cl}_{8}\right)\right]$ and $\mathrm{PcLu}\left[\mathrm{PcCl}_{16}\right]$ are the bonding and antibonding combinations of the phthalocyanine $\mathrm{a}_{1 \mathrm{u}}$ frontier orbitals. However, these two $\mathrm{a}_{1 \mathrm{u}}$ orbitals are no longer degenerate since they belong to different phthalocyanine ligands. As said above, the frontier orbitals of the chlorinated phthalocyanine lie at lower energy than those of the non-substituted Pc. The non degenerate $\mathrm{a}_{1 \mathrm{u}}$ interaction is sketched on the right side of Scheme 2. It follows that the bonding combination has a larger contribution of the lower $\mathrm{a}_{1 \mathrm{u}}$ orbital, i.e. $\mathrm{PcCl}_{n}$, whereas the antibonding counterpart has a dominant Pc localization. As a consequence, the unpaired electron of the neutral species has a more important localization on the non-substituted Pc ligand. The mixing between the $\mathrm{a}_{1 \mathrm{u}}(\mathrm{Pc})$ and $\mathrm{a}_{1 \mathrm{u}}\left(\mathrm{PcCl}_{n}\right)$ orbitals depends on their energy difference $\Delta E$. The smaller (larger) $\Delta E$, the larger (smaller) the mixing. Thus, the lower the energy of $\mathrm{a}_{1 \mathrm{u}}\left(\mathrm{PcCl}_{n}\right)$, the smaller the mixing and the more Pc-polarized the unpaired electron of the neutral species. In other words, the density of the unpaired electron on the non-substituted phthalocyanine ring increases with the number of $\mathrm{Cl}$ atoms on the chlorinated phthalocyanine. This trend is nicely reproduced by the computed data (Table 1) which show that the Pc participation in the $2 \mathrm{a}_{2} \mathrm{MO}$ of the various computed models increases with the number of $\mathrm{Cl}$ atoms. This is also illustrated by the plots of the SOMO of the neutral species shown in Fig. 5. Consistently, the DFT-computed spin density on the Pc ligand increases when going from $\mathrm{LuPc}_{2}(0.5)$ to $\mathrm{PcLu}\left[\mathrm{PcCl}_{16}\right](0.68)$. It is close to 0.6 in both $\mathrm{PcLu}\left[\mathrm{PcCl}_{8}\right]$ isomers. It is noteworthy that in all the $\mathrm{PcLu}\left[\mathrm{PcCl}_{n}\right]$ complexes, the $\mathrm{PcCl}_{n}$ Mulliken charge is more negative than that of the Pc one, despite the fact that the unpaired electron is more localized on Pc. The explanation lies in the electron withdrawing effect of the chlorine atoms which act as global attractors on the whole electron density. As a matter of fact, this polarization effect is largely independent from the oxidation state of the $\mathrm{PcLu}\left[\mathrm{PcCl}_{n}\right]^{+/ 0 /-}$ species, i.e., from the occupation number of the $2 \mathrm{a}_{2} \mathrm{MO}$.

The bonding mode is very similar in all the computed species and involves only the $5 \mathrm{~d} \mathrm{Lu}$ orbitals. Indeed, the atomic 4f Mulliken population is unsurprisingly found to be always almost equal to 14 (no electron donation to the ligands), whereas the $6 \mathrm{~s}$ and $6 \mathrm{p}$ populations are never significantly different from zero (no donation from the ligands). On the other hand, the formally vacant $5 \mathrm{~d}$ orbitals of $\mathrm{Lu}(\mathrm{III})$ in $\left[\mathrm{LuPc}_{2}\right]^{+}$receive 1.41 electron from the ligands, indicating significant covalent interaction. This transfer decreases slightly to 1.38 and 1.37 in the more reduced forms $\mathrm{LuPc}_{2}$ and $\left[\mathrm{LuPc}_{2}\right]^{-}$, respectively. This is the consequence of the larger repulsion between the ligands in the reduced forms which in turn slightly weakens the metal-ligand covalent bonding interaction. Slightly lower $5 \mathrm{~d}$ populations are computed in the chlorinated derivatives, the smaller ones corresponding to the $\mathrm{PcLu}\left[\mathrm{PcCl}_{16}\right]^{+/ 0 /-}$ series $(1.38,1.36$ and 1.34 , respectively). To get a better insight into the metal-ligand bonding, we have carried out a decomposition of the energy corresponding to the interaction between the $\mathrm{Lu}^{3+}$ cation and the ligand system in a similar way as Ricciardi et al. for metal bisporphyrin complexes. ${ }^{33}$ The calculations were carried out on the closed-shell $\mathrm{PcLu}\left[\mathrm{PcCl}_{n}\right]^{ \pm}$couples. The total bonding energy is decomposed in the usual way into the sum of the orbital interaction energy and the steric interaction energy, the latter being the sum of a Pauli repulsion term and of an electrostatic term. The corresponding computed values are given in Table 2. Considering first the four cationic species, one can see that the Pauli repulsion and the orbital interaction energies vary little across the series, as compared to the electrostatic interaction energy term which dominates the total interaction energy. The electron withdrawing character of the chlorine atoms tends to reduce the negative charge on the coordinated nitrogens, thus lowering the strength of the electrostatic interaction. Adding two electrons to the cationic species does not modify this effect that much since these two electrons cannot interact by symmetry with the metal valence orbitals. Thus, in the case of the anionic series, the total interaction energy is also dominated by its electrostatic component and a trend similar to that of the cationic series is observed. Finally, it should be noticed that the energy decomposition described above does not take into account 
Table 2 Two-fragment energy decomposition of $\mathrm{PcLu}\left[\mathrm{PcCl}_{n}\right]^{ \pm}$. Cation fragments: $\mathrm{Lu}^{+3}$ and $\left\{\mathrm{Pc}+\left[\mathrm{PcCl}_{n}\right]\right\}^{2-}$; anion fragments: $\mathrm{Lu}^{+3}$ and $\left\{\mathrm{Pc}+\left[\mathrm{PcCl}_{n}\right]\right\}^{4-}$

\begin{tabular}{|c|c|c|c|c|c|c|c|c|}
\hline & \multicolumn{2}{|c|}{$\underline{\left[\mathrm{LuPc}_{2}\right]^{q} C_{4 \mathrm{v}}}$} & \multicolumn{2}{|c|}{$\operatorname{PcLu}\left[\operatorname{Pc}\left(\mathrm{p}-\mathrm{Cl}_{8}\right)\right]^{q} C_{4 \mathrm{v}}$} & \multicolumn{2}{|c|}{$\underline{\mathrm{PcLu}}\left[\mathrm{Pc}\left(\mathrm{np}-\mathrm{Cl}_{8}\right)\right]^{q} C_{4 \mathrm{v}}$} & \multicolumn{2}{|c|}{$\mathrm{PcLu}\left[\mathrm{PcCl}_{16}\right]^{q} C_{4 \mathrm{v}}$} \\
\hline & $q=+1$ & $q=-1$ & $q=+1$ & $q=-1$ & $q=+1$ & $q=-1$ & $q=+1$ & $q=-1$ \\
\hline Pauli repulsion energy/eV & 9.20 & 8.66 & 9.35 & 8.55 & 9.12 & 8.41 & 9.01 & 8.43 \\
\hline Electrostatic Interaction energy/eV & -31.38 & -45.65 & -29.94 & -43.47 & -30.76 & -44.65 & -29.61 & -43.24 \\
\hline Total steric interaction energy/eV & -22.18 & -36.99 & -20.58 & -34.92 & -21.63 & -36.24 & -20.60 & -34.81 \\
\hline Orbital interaction energy/eV & -26.07 & -25.98 & -26.33 & -26.07 & -25.99 & -25.64 & -25.99 & -25.69 \\
\hline Total bonding energy/eV & -48.25 & -62.97 & -46.92 & -60.99 & -47.62 & -61.88 & -46.59 & -60.50 \\
\hline
\end{tabular}

the repulsive interaction energy between the two phthalocyanine ligands, which is not negligible. For example, it was computed to be $2.9 \mathrm{eV}$ and $9.5 \mathrm{eV}$ in the case of $\left[\mathrm{LuPc}_{2}\right]^{+}$and $\left[\mathrm{LuPc}_{2}\right]^{-}$.

A good way to test the quality of the DFT results described above is the correlation of the computed ionization potentials and electron-affinities of the neutral species with their experimental oxidation and reduction potentials, respectively. The experimental redox potentials are those of the $t \mathrm{Bu}$ derivatives $\mathrm{Lu}\left[\left(t \mathrm{Bu}_{4}\right) \mathrm{Pc}\right]_{2}, \quad\left[\left(t \mathrm{Bu}_{4}\right) \mathrm{Pc}\right] \mathrm{Lu}\left[\mathrm{Pc}\left(\mathrm{p}-\mathrm{Cl}_{8}\right)\right], \quad$ and $\left[\left(t \mathrm{Bu}_{4}\right) \mathrm{Pc}\right] \mathrm{Lu}\left[\mathrm{PcCl}_{16}\right]$. We have evaluated those of $\left[\left(t \mathrm{Bu}_{4}\right) \mathrm{Pc}\right] \mathrm{Lu}\left[\mathrm{Pc}\left(\mathrm{np}-\mathrm{Cl}_{8}\right)\right]$ through calculations using Hammett coefficients. ${ }^{34}$ The corresponding curves (Fig. 7) exhibit the expected qualitative linear correlations with very satisfying agreement, especially if one consider that the computed and experimental series are not exactly the same. This consistency between computed and experimental data brings full confidence in the whole theoretical results.

The opportunity of having determined the DFT wavefunctions of a whole family of lutetium bisphthalocyanines offered us the possibility of carrying out TDDFT calculations (see computational details) to calculate their major optical transitions and to rationalize their experimental spectra. We start with the description of the experimental UV-visible spectrum of $\mathrm{LuPc}_{2}$ (recorded in $\mathrm{CH}_{2} \mathrm{Cl}_{2}$ ), shown in Fig. 8 together with the attributions of the major transitions as generally given in the literature.

The intense Soret band is associated with inter-phthalocyanine allowed transitions. ${ }^{12,15,30}$ The next band is known as the blue vibronic band (BV) and is due to various transitions which are forbidden in the idealized $D_{4 \mathrm{~h}}$ or $D_{4 \mathrm{~d}}$ symmetry. ${ }^{12,30}$ As for the Soret band, the $Q$ band (and its vibronic component $Q_{\text {vib}}$ ) is associated with various allowed transitions. ${ }^{30 a}$ The weak band around $900 \mathrm{~nm}$ results from a forbidden transition involving the SOMO. It is known as the red vibronic band (RV) and is, as well as the $\mathrm{BV}$ band, characteristic of the radical nature of $\mathrm{LuPc}_{2}$. Finally, a broad inter-valence band (IVB), not recorded on the spectrum of Fig. 8 but observed in the $1100-1600 \mathrm{~nm}$ range, is attributed to a HOMO-SOMO transition and sometimes described as associated with a charge transfer between the two macrocycles. ${ }^{15,12,30,31}$

The experimental $\lambda_{\max }$ associated with the above described bands are reported in Table 3 for $\left(\mathrm{LuPc}_{2}\right)^{+/ 0 /-1}$, together with the values corresponding to the major computed transitions (oscillator strength in parentheses) for the $\left(\mathrm{LuPc}_{2}\right)^{+/ 0 /-1}, \operatorname{PcLu}\left[\mathrm{Pc}\left(\mathrm{p}-\mathrm{Cl}_{8}\right)\right]^{+/ 0 /-1}, \operatorname{PcLu}\left[\mathrm{Pc}\left(\mathrm{np}-\mathrm{Cl}_{8}\right)\right]^{+/ 0 /-1}$ and $\mathrm{PcLu}\left[\mathrm{PcCl}_{16}\right]^{+/ 0 /-1}$ series. The simulated spectra of the $\left(\mathrm{LuPc}_{2}\right)^{+/ 0 /-1}$ series are shown in Fig. 9. Because of the large
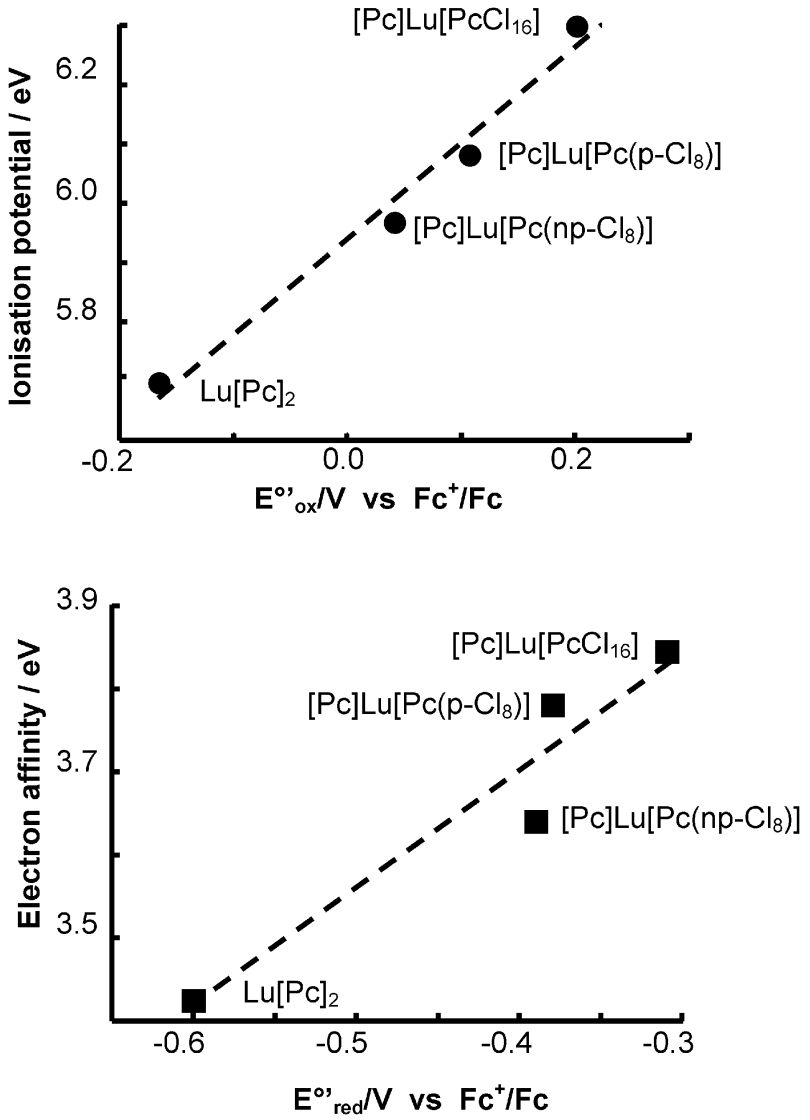

Fig. 7 Computed ionization potentials of the neutral species vs. electrochemical oxidation potentials (top) and computed electron affinities vs. electrochemical reduction potentials (bottom). Redox potentials are those of the $\left[\left(t \mathrm{Bu}_{4}\right) \mathrm{Pc}\right] \mathrm{Lu}\left[\mathrm{Pc}\left(\mathrm{np}-\mathrm{Cl}_{n}\right)\right]$ derivatives. The redox potentials of $\left[\left(t \mathrm{Bu}_{4}\right) \mathrm{Pc}\right] \mathrm{Lu}\left[\mathrm{Pc}\left(\mathrm{np}-\mathrm{Cl}_{8}\right)\right]$ have been evaluated using Hammett coefficients.

computing effort required, the transitions associated with the Soret band were not calculated.

There is a good agreement between the experimental and computed transitions of $\mathrm{LuPc}_{2}$. Calculations predict the $1 \mathrm{a}_{2} \rightarrow 2 \mathrm{a}_{2}$ IVB transition to lie around $1300 \mathrm{~nm}$. This value is close to the reported experimental one, ${ }^{30,31}$ suggesting that the Born-Oppenheimer approximation is still valid for this transition, thus supporting the fully delocalized nature of the unpaired electron. The RV band can be approximated to a $2 \mathrm{a}_{2}$ $(\mathrm{SOMO}) \rightarrow 2 \mathrm{e}$ (LUMO +1$)\left(\mathrm{a}_{2} \rightarrow \mathrm{e}_{3}\right.$ in $D_{4 \mathrm{~d}}$ symmetry) transition $(78 \%)$, in agreement with an earlier indexation, ${ }^{30 a}$ together with some $2 \mathrm{a}_{2} \rightarrow 1$ e admixture $(20 \%)$. Its small 


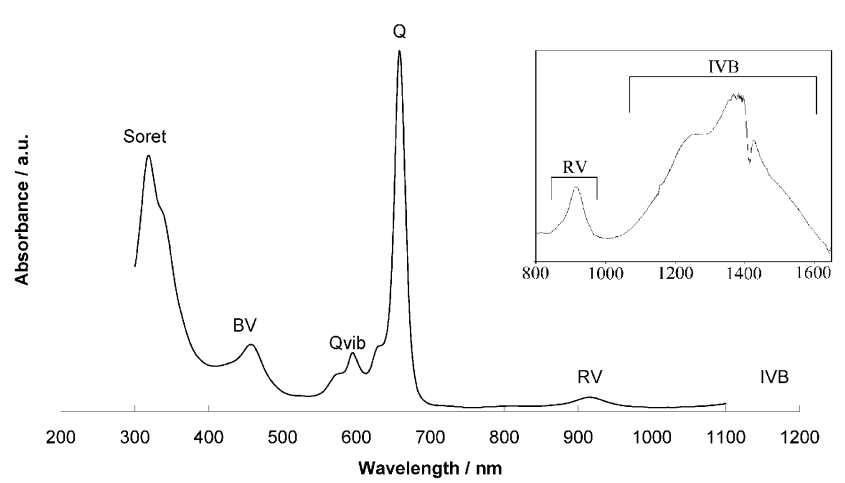

Fig. 8 Experimental UV-vis spectrum of $\mathrm{LuPc}_{2}$ in $\mathrm{CH}_{2} \mathrm{Cl}_{2}$.

oscillator strength comes from the strong pseudo- $D_{4 \mathrm{~d}}$ symmetry of the complex which renders the transition almost forbidden. However, vibronically allowed transitions are responsible for the observation of this band. ${ }^{30}$ The major components of the $Q$ band are found to be mainly associated with transitions from two occupied ligand levels of e symmetry to the $2 \mathrm{a}_{2}$ SOMO. Of course, the experimental $Q_{\mathrm{v}}$ band is not computed since it involves vibronic states. The BV band is mainly associated with $1 \mathrm{a}_{1} \rightarrow 2 \mathrm{a}_{2}$ and $1 \mathrm{~b}_{1} \rightarrow 2 \mathrm{a}_{2}$ transitions. As for the RV band, associated vibronically allowed transitions are responsible for the observation of this band. ${ }^{30 a}$ Although satisfying, the agreement between experiment and calculations in the case of the oxidized and reduced forms of $\mathrm{LuPc}_{2}$ is not as good as in the case of the neutral species. This is probably due to the fact that the calculations do not take into account the solvent and counter-ion effects, which are likely not to be negligible in the absorption phenomenon, of these ionic species in solution. Nevertheless, the experimental $\lambda_{\max }$ values of $\left[\mathrm{LuPc}_{2}\right]^{+}$and $\left[\mathrm{LuPc}_{2}\right]^{-}$could be easily indexed to calculated transitions. They are associated with the same excitations as for the neutral form. In the particular case of $\left[\mathrm{LuPc}_{2}\right]^{+}$, a weak absorption band (not reported in Table 3) appears in the RV

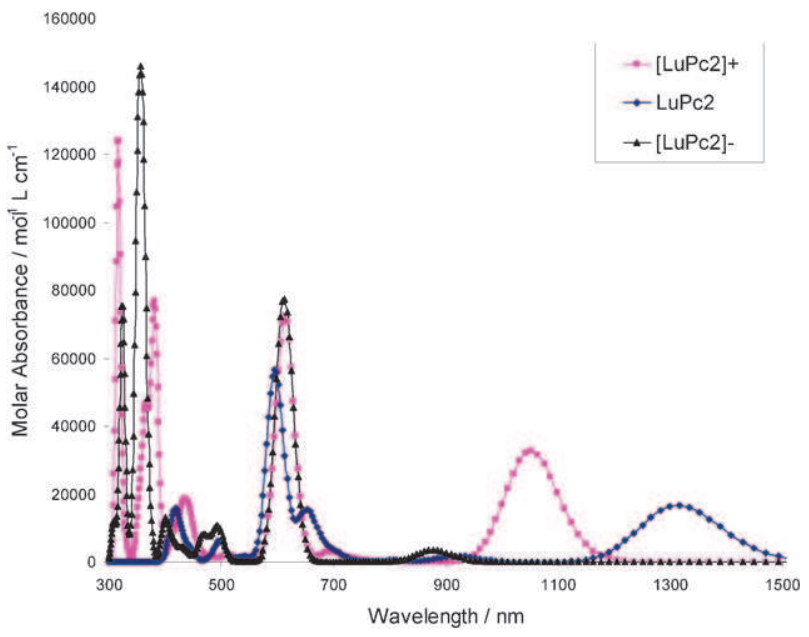

Fig. 9 Simulated absorption spectra of $\left(\mathrm{LuPc}_{2}\right)^{+/ 0 /-1}$. The Soret band was not calculated for the neutral species.

region of the experimental spectrum. It is assigned by the calculations to a forbidden $1 b_{2} \rightarrow 2 a_{2}$ transition. The chlorinesubstituted series exhibits similar features in their simulated spectra (Table 3 and Fig. 9).

\section{Conclusion}

This paper reports the first theoretical investigation on a series of unsymmetrical bisphthalocyanine lutetium complexes. The electronic structure of $\mathrm{PcLu}\left[\mathrm{Pc}\left(\mathrm{p}-\mathrm{Cl}_{8}\right)\right], \mathrm{PcLu}\left[\mathrm{Pc}\left(\mathrm{np}-\mathrm{Cl}_{8}\right)\right]$ and $\mathrm{PcLu}\left[\mathrm{PcCl}_{16}\right]$ indicates that, contrarily to the symmetrical $\mathrm{LuPc}_{2}$ complex which exhibits an unpaired electron equally delocalized on both phthalocyanine ligands, the unsymmetrical ones have their unpaired electron predominantly localized on the non-substituted ligand. Although this fact can be rationalized on the basis of orbital interaction arguments, it is at first sight counter-intuitive since the chlorinated phthalocyanine is the most electron withdrawing ligand.

Table 3 Experimental $\lambda_{\max }$ values (in $\mathrm{nm}$ ) recorded in dichloromethane for $\left(\mathrm{LuPc}_{2}\right)^{+/ 0 /-}$, together with the corresponding computed transitions for $\left(\mathrm{LuPc}_{2}\right)^{+/ 0 /-1}, \mathrm{PcLu}\left[\mathrm{Pc}\left(\mathrm{p}-\mathrm{Cl}_{8}\right)\right]^{+/ 0 /-1}, \mathrm{PcLu}\left[\mathrm{Pc}\left(\mathrm{np}-\mathrm{Cl}_{8}\right)\right]^{+/ 0 /-1}$ and $\mathrm{PcLu}\left[\mathrm{PcCl}_{16}\right]^{+/ 0 /-1}$. The first value (when available) is experimental; the bold value is computed and its oscillator strength $\times 10^{-5}$ is given in parenthesis

\begin{tabular}{|c|c|c|c|c|c|}
\hline & $\begin{array}{l}\text { Soret (experimental } \\
\text { values only) }\end{array}$ & $\mathrm{BV}$ & Q & RV & IVB \\
\hline \multicolumn{6}{|l|}{$\mathrm{Lu}[\mathrm{Pc}]_{2}$} \\
\hline Neutral & 320 & $456 / 497(2)$ & $595,658 / 596(\mathbf{2 4}), \mathbf{6 5 2}(7)$ & $-878(2)$ & $1314(8)$ \\
\hline Anionic & 275,334 & & $618,698 / 612(36)$ & & \\
\hline \multicolumn{6}{|c|}{$\mathrm{PcLu}\left[\mathrm{Pc}\left(\mathrm{p}-\mathrm{Cl}_{8}\right)\right]$} \\
\hline Cationic & & $598(2), 591(1)$ & $653(17)$ & $928(1)$ & $1087(14)$ \\
\hline Neutral & & $486(2), 473(1)$ & $619(32), 690(4)$ & $826(1)$ & $1332(7)$ \\
\hline Anionic & & & $624(39)$ & & \\
\hline \multicolumn{6}{|c|}{$\mathrm{PcLu}\left[\mathrm{Pc}\left(\mathrm{np}-\mathrm{Cl}_{8}\right)\right]$} \\
\hline Cationic & & $553(3), 573(5)$ & $624(6), 682(11)$ & $717(15)$ & 1423 \\
\hline Neutral & & $502(1), 521(3)$ & $607(7), 656(10)$ & $599(5)$ & 1679 \\
\hline Anionic & & $474(8)$ & & & \\
\hline \multicolumn{6}{|c|}{$\mathrm{PcLu}\left[\mathrm{PcCl}_{16}\right]$} \\
\hline Cationic & & $562(6), 585(3)$, & 799 (10), 687 (13) & $737(8), 732(1)$ & $1480(9)$ \\
\hline Neutral & & $513(1), 518(3), 525(2)$ & $663(12)$ & & $1701(7)$ \\
\hline Anionic & & $478(3), 513(2), 542(5)$ & $665(39)$ & & \\
\hline
\end{tabular}




\section{Computational details}

Density functional theory (DFT) calculations were carried out on the studied compounds using the Amsterdam Density Functional (ADF) program $^{35}$ developed by Baerends and coworkers. ${ }^{36}$ Electron correlation was treated within the local density approximation (LDA) in the Vosko-Wilk-Nusair parametrization. ${ }^{37}$ The non-local corrections of Becke and Perdew were added to the exchange and correlation energies, respectively. ${ }^{38,39}$ The numerical integration procedure applied for the calculations was developed by te Velde et al. ${ }^{36 e}$ Relativistic corrections were added using the Zeroth Order Regular Approximation (ZORA) scalar Hamiltonian. ${ }^{40}$ The atom electronic configurations were described by a triple- $\zeta$ Slater-type orbital (STO) basis set for H 1s, C 2s and 2p, N 2s and $2 \mathrm{p}$ and $\mathrm{Cl} 3 \mathrm{~s}$ and $3 \mathrm{p}$ augmented with a $3 \mathrm{~d}$ single- $\zeta$ polarization function for $\mathrm{C}, \mathrm{N}$ and $\mathrm{Cl}$ atoms and with a $2 \mathrm{p}$ single- $\zeta$ polarization function for $\mathrm{H}$. A triple- $\zeta$ STO basis set was used for $\mathrm{Lu} 4 \mathrm{f}, 5 \mathrm{~d}$ and $6 \mathrm{~s}$, a double- $\zeta$ basis for $\mathrm{Lu} 5 \mathrm{~s}$ and $5 p$ augmented with a single- $\zeta 6 \mathrm{p}$ polarization function for $\mathrm{Lu}$ atom. A frozen-core approximation was used to treat the core shells up to $1 \mathrm{~s}$ for $\mathrm{C}$ and $\mathrm{N}, 2 \mathrm{p}$ for $\mathrm{Cl}$ and $4 \mathrm{~d}$ for $\mathrm{Lu}$. Full geometry optimizations were carried out using the analytical gradient method implemented by Verluis and Ziegler. ${ }^{41}$ Spin-unrestricted calculations were performed for all the openshell systems. The fragment interaction energy decomposition was made according to the method proposed by Ziegler and coworkers. ${ }^{42}$ In the case of the $\mathrm{PcLu}\left[\mathrm{PcCl}_{n}\right]^{+}$cations, the considered fragments were $\mathrm{Lu}^{+3}$ and $\left\{\mathrm{Pc}+\left[\mathrm{PcCl}_{n}\right]\right\}^{2-}$, the electron configuration of the latter being $\left(1 \mathrm{a}_{2}\right)^{2}\left(2 \mathrm{a}_{2}\right)^{0}$ (see Scheme 2). In the case of the $\mathrm{PcLu}\left[\mathrm{PcCl}_{n}\right]^{-}$anions, the considered fragments were $\mathrm{Lu}^{+3}$ and $\left\{\mathrm{Pc}+\left[\mathrm{PcCl}_{n}\right]\right\}^{4-}$, the electron configuration of the latter being $\left(1 \mathrm{a}_{2}\right)^{2}\left(2 \mathrm{a}_{2}\right)^{2}$.

The UV-visible transitions were calculated by means of time-dependent DFT (TDDFT) calculations, ${ }^{43}$ at the same level of theory. Only spin-allowed transitions have been taken into account. Moreover, only transitions with non negligible oscillator strengths are reported and discussed.

Representation of the molecular structures were done using MOLEKEL $4.1{ }^{44}$ The UV/Visible spectra have been simulated from the computed TDDFT data and their oscillated strengths by using the SWizard program, ${ }^{45}$ each transition being associated with a Gaussian function of half-height width equal to $1000 \mathrm{~cm}^{-1}$.

\section{Acknowledgements}

The authors thank the Institut de Développement et de Ressources en Informatique Scientifique (IDRIS-CNRS, Orsay) for computing facilities. JYS thanks the Institut Universitaire de France (IUF) for financial support.

\section{References}

1 A. T. Chang and J. C. Marchon, Inorg. Chim. Acta, 1981, 53, L241.

2 (a) A. De Cian, M. Moussavi, J. Fischer and R. Weiss, Inorg. Chem., 1985, 24, 3162; (b) M. Moussavi, A. De Cian, J. Fischer and R. Weiss, Inorg. Chem., 1988, 27, 1287.

3 (a) N. Ishikawa, O. Ohno and Y. Kaizu, Chem. Phys. Lett., 1991, 180, 51; (b) N. Ishikawa, O. Ohno, Y. Kaizu and N. Kobayashi, J. Phys. Chem., 1992, 96, 8832.
4 F. Guyon, A. Pondaven, P. Guenot and M. L'Her, Inorg. Chem., 1994, 33, 4787-4793.

5 D. K. P. Ng and J. Jiang, Chem. Soc. Rev., 1997, 26, 433.

6 N. Ishikawa, O. Ohno and Y. Kaizu, J. Phys. Chem., 1993, 97, 1004.

7 D. Chabach, M. Tahiri, A. De Cian, J. Fischer, R. Weiss and M. El Malouli Bibout, J. Am. Chem. Soc., 1995, 117, 8548.

8 R. Guilard, J. M. Barbe, A. Ibnlfassi, A. Zrineh, V. A. Adamian and K. M. Kadish, Inorg. Chem., 1995, 34, 1472.

9 J. Jiang, K. Kasuga and D. P. Arnold, Sandwich-type phthalocyaninato and porphyrinato metal complexes, in Supramolecular Photosensitive and electroactive materials, ed. H. S. Nalwa, Academic Press, New York, 2001, pp. 113-210.

10 K. M. Kadish, G. Moninot, Y. Hu, D. Dubois, A. Ibnlfassi, J. M. Barbe and R. Guilard, J. Am. Chem. Soc., 1993, 115, 8153.

11 A. Mentec, A. Pondaven, J.-M. Kerbaol and M. L'Her, Inorg. Chem. Commun., 2006, 810.

12 (a) E. Orti and J.-L. Bredas, J. Chem. Phys., 1988, 89, 1009; (b) E. Orti, J.-L. Brédas and C. Clarisse, J. Chem. Phys., 1990, 92, 1228; (c) E. Orti and J.-L. Brédas, J. Am. Chem. Soc., 1992, 114, 8669; (d) V. Lemaur, M. Steel, D. Beljonne, D. J.-L. Brédas and J. Cornil, J. Am. Chem. Soc., 2005, 127, 6077.

13 (a) A. Rosa and E. J. Baerends, Inorg. Chem., 1993, 32, 5637; (b) A. Rosa and E. J. Baerends, Inorg. Chem., 1994, 33, 584; (c) G. Ricciardi, A. Rosa and E. J. Baerends, J. Phys. Chem., 2001, 105, 5242 .

14 K. Toyota, J. Hasegawa and H. J. Nakatsuji, J. Phys. Chem., 1997, 101, 446.

15 (a) J. Mack and M. J. Stillman, Inorg. Chem., 1997, 36, 413; (b) J. Mack and M. J. Stillman, J. Porphyrins Phthalocyanines, 2001, 5, 67; (c) J. Mack and M. J. Stillman, Coord. Chem. Rev., 2001, 219-221, 993; (d) S. P. Keizer, J. Mack, B. A. Bench, S. M. Gorun and M. J. Stillman, J. Am. Chem. Soc., 2003, 125, 7067.

16 (a) J. Mack, N. Kobayashi, C. C. Leznoff and M. J. Stillman, Inorg. Chem., 1997, 36, 5624; (b) J. Mack, Y. Asano, N. Kobayashi and M. J. Stillman, J. Am. Chem. Soc., 2005, 127, 17697; (c) J. Mack, M. J. Stillman and N. Kobayashi, Coord. Chem. Rev., 2007, 251, 429.

17 (a) N. Kobayashi and H. Konami, Phthalocyanines, 1996, 4, 343; (b) N. Kobayashi, S.-I. Nakajima, H. Ogata and T. Fukuda, Chem.-Eur. J., 2004, 10, 6294; (c) A. Muranaka, Y. Matsumoto, M. Uchiyama, J. Jiang, Y. Bian, A. Ceulemans and N. Kobayashi, Inorg. Chem., 2005, 44, 3818.

18 (a) N. Ishikawa, J. Porphyrins Phthalocyanines, 2001, 5, 87; (b) S. Takamatsu and N. Ishikawa, Polyhedron, 2007, 26, 1859.

19 (a) E. M. Bauer, M. P. Donzello, C. Ercolani, E. Masetti, S. Panero, G. Ricciardi, A. Rosa, A. Chiesi-Villa and C. Rizzoli, Inorg. Chem., 2003, 42, 283; (b) T. C. Gunaratne, A. V. Gusev, X. Peng, A. Rosa, G. Ricciardi, E. J. Baerends, C. Rizzoli, M. E. Kenney and M. A. J. Rodgers, J. Phys. Chem. A, 2005, 109, 2078; (c) A. V. Soldatova, J. Kim, X. Peng, A. Rosa, G. Ricciardi, M. E. Kenney and M. A. Rodgers, Inorg. Chem., 2007, 46, 2080.

20 (a) Y. Zhang, X. Zhang and J. Jiang, THEOCHEM, 2004, 673, 103; (b) Y. Zhang, X. Zhang, Z. Liu, Y. Bian and J. Jiang, J. Phys. Chem. A, 2005, 109, 6363; (c) Z. Liu, X. Zhang, Y. Zhang and Y. Jiang, Vib. Spectrosc., 2007, 43, 447; (d) Y. Zhang, X. Cai, H. Xu, Z. Liu and J. Jiang, Int. J. Quantum Chem., 2007, 107, 952; (e) Y. Zhang, X. Cai, Y. Zhou, X. Zhang, H. Xu, Z. Liu, X. Li and J. Jiang, J. Phys. Chem. A, 2007, 111, 392; (f) Z. Liu, X. Zhang, Y. Zhang and Y. Jiang, Spectochim. Acta A, 2007, 67, 1232.

21 F. Evangelista, V. Carravetta, G. Stefani, B. Jansik, M. Alagia, S. Stranges and A. Ruocco, J. Chem. Phys., 2007, 126, 124709.

22 (a) G. I. Cárdenas-Jirón, M. A. Gulppi, C. A. Caro, R. del Río, M. Páez and J. H. Zagal, Electrochim. Acta, 2001, 46, 3227; (b) G. I. Cárdenas-Jirón, J. Phys. Chem. A, 2002, 106, 3202; (c) G. I. Cárdenas-Jirón, V. Paredes-Garciá, D. Venegas-Yazigi, J. H. Zagal, M. Páez and J. Costamagna, J. Phys. Chem. A, 2006, 110, 11870; $(d)$ C. Berríos, G. I. Cárdenas-Jirón, J. F. Marco, C. Gutiérrez and M. S. Ureta-Zaňartu, J. Phys. Chem. A, 2007, 111, 2706.

23 R. Rousseau, R. Aroca and M. L. Rodríguez-Méndez, J. Mol. Struct., 1995, 356, 49. 
24 (a) M.-S. Liao and S. J. Scheiner, J. Comput. Chem., 2002, 23, 1391; (b) M.-S. Liao, J. D. Watts, M.-J. Huang, S. M. Gorun, T. Kar and S. Scheiner, J. Chem. Theory Comput., 2005, 1, 1201; (c) M.-S. Liao, J. D. Watts and M.-J. Huang, J. Comput. Chem., 2006, 27, 1577.

25 (a) X. D. Gong, H. M. Xiao and H. Tian, Int. J. Quantum Chem., 2002, 86, 531; (b) X. D. Gong, H. M. Xiao, P. Gao and H. Tian, Int. J. Quantum Chem., 2002, 88, 331; (c) X. D. Gong, H. M. Xiao and H. Tian, THEOCHEM, 2002, 593, 93.

26 P. N. Day, Z. Wang and R. Pachter, THEOCHEM, 1998, 455, 33 .

27 (a) N. El Khatib, B. Boudjema, M. Maitrot, H. Chermette and L. Porte, Can. J. Chem., 1988, 66, 2313; (b) N. El Khatib, B. Boudjema, G. Guillaud, M. Maitrot and H. Chermette, J. Less-Common Met., 1988, 143, 101.

28 (a) V. N. Nemykin, R. G. Hadt, R. V. Belosludov, H. Misuseki and Y. Kawasoe, J. Phys. Chem. A, 2007, 111, 12901; (b) K. Serbert, I. Deǵirmencioǵlu, Y. Unnver, M. Er, C. Kantar and K. Sancak, J. Organomet. Chem., 2007, 692, 5646; (c) N. Marom, O. Hod, G. E. Scuseria and L. Kronik, J. Chem. Phys., 2008, 128, 164107; (d) T. Strenalyuk, S. Samdal and H. V. Volden, J. Phys. Chem. A, 2008, 112, 4853.

29 (a) K. Kasuga, M. Tsutsui, R. C. Petterson, K. Tatsumi, N. Van Opdenbosch, G. Pepe and E. F. Meyer, J. Am. Chem. Soc., 1980, 102, 4835; (b) J. L. Paillaud, M. Drillon, A. De Cian, C. M. Fischer, R. Weiss and G. Villeneuve, Phys. Rev. Lett., 1991, 67, 244

30 (a) T. C. VanCott, Z. Gasyna, P. N. Schatz and M. E. Boyle, J. Phys. Chem., 1995, 99, 4820; (b) Z. Gasyna, P. N. Schatz and M. E. Boyle, J. Phys. Chem., 1995, 99, 10159.

31 J. Zhang, F. Lu, H. Huang, J. Wang, H. Yu, J. Jiang, D. Yan and Z. Wang, Synth. Met., 2005, 148, 123.

32 S. Takamasu, T. Ishikawa, S.-Y. Koshihara and N. Ishikawa, Inorg. Chem., 2007, 46, 7250.

33 G. Ricciardi, A. Rosa, E. J. Baerends and S. A. van Gisbergen, J. Am. Chem. Soc., 2002, 124, 12319.

34 (a) K. Kadish, The Electrochemistry of Metalloporphyrins in Nonaqueous Media, in Progress in Inorganic Chemistry-volume 34, ed. S. J. Lippard, J. Wiley, New York, 2001, pp. 435-605; (b) A. Giraudeau, H. J. Callot and M. Gross, Inorg. Chem., 1979, 18, 201.

35 ADF version 2006.01, Theoretical Chemistry, Vrije Universiteit, Amsterdam, The Netherlands, Scientific Computing and Modelling (SCM).

36 (a) E. J. Baerends, D. E. Ellis and P. Ros, Chem. Phys., 1973, 2, 41; (b) G. te Velde and E. J. Baerends, J. Comput. Phys., 1992, 99, 84; (c) C. Fonseca Guerra, J. C. Snijders, G. te Velde and E. J. Baerends, Theor. Chim. Acc., 1998, 99, 391; (d) F. M. Bickelhaupt and E. J. Baerends, Rev. Comput. Chem., 2000, 15, 1; (e) G. te Velde, F. M. Bickelhaupt, C. Fonseca Guerra, S. J. A. van Gisbergen, E. J. Baerends, J. G. Snijders and T. J. Ziegler, J. Comput. Chem., 2001, 22, 931.

37 S. D. Vosko, L. Wilk and M. Nusair, Can. J. Chem., 1990, 58, 1200. 38 (a) A. D. Becke, J. Chem. Phys., 1986, 84, 4524; (b) A. D. Becke, Phys. Rev. A, 1988, 38, 3098.

39 (a) J. P. Perdew, Phys. Rev. B, 1986, 33, 8822; (b) J. P. Perdew, Phys. Rev. B, 1986, 34, 7406.

40 (a) E. van Lenthe, E. J. Baerends and J. G. Snijders, J. Chem. Phys., 1993, 99, 4597; (b) E. van Lenthe, E. J. Baerends and J. G. Snijders, J. Chem. Phys., 1994, 101, 9783; (c) E. van Lenthe, R. van Leeuwen and E. J. Baerends, Int. J. Quantum Chem., 1996, 57, 281; (d) E. van Lenthe, E. J. Baerends and J. G. Snijders, J. Chem. Phys., 1996, 105, 6505; (e) E. van Lenthe, A. Ehlers and E. Baerends, J. Chem. Phs., 1999, 110, 8943.

41 L. Verluis and T. Ziegler, J. Chem. Phys., 1988, 88, 322.

42 (a) T. Ziegler and A. Rauk, Inorg. Chem., 1979, 18, 1558; (b) T. Ziegler and A. Rauk, Inorg. Chem., 1979, 18, 1755; (c) F. M. Bickelhaupt and E. J. Baerends, in Reviews of Modern Physics, ed. K. B. Lipkowitz and D. B. Boyd, Wiley, New York, 2000, vol. 15 , pp. $1-86$.

43 (a) S. J. A. van Gisbergen, J. G. Snijders and E. J. Baerends, Comput. Phys. Commun., 1999, 118, 119; (b) A. Rosa, E. J. Baerends, S. J. A. Gisbergen, E. van Lenthe, V. Groeneveld and J. G. Snijders, J. Am. Chem. Soc., 1999, 121, 10356.

44 P. Flükiger, H. P. Lüthi, S. Portmann and J. Weber, Swiss Center for Scientific Computing (CSCS), Switzerland, 2000-2001.

45 S. I. Gorelsky, SWizard program, http://www.sg-chem.net, University Of Ottawa, Canada, 2007. 